\title{
Sonar mapping ventures into uncharted waters
}

Ships cruising the globe may soon be able to help scientists to chart seamounts rising from the ocean floor.

Less than $1 \%$ of the 47,000 known seamounts standing taller than 500 metres have been mapped in detail. In 2005, the dangers this poses became clear when the nuclear submarine USS San Francisco, travelling submerged about 600 kilometres south of Guam, struck an uncharted seamount, damaging the vessel and killing a sailor.

A new system using a basic GPS device coupled to a computer would allow anything from freight ships to pleasure yachts carrying sonar to help chart seamounts, which could number as high as 200,000 , oceanographers say.

The initiative is an outgrowth of the Seamounts '09 Workshop, held 19-21 March at the Scripps Institution of Oceanography in La Jolla, California. The idea is to take advantage of single-beam and multi-beam sonar now aboard many vessels. "This is a really cool opportunity to take the baby step to image these features," says meeting chairman Hubert Staudigel of Scripps.

Theoretically, any vessel could gather data from regions of interest, but the quality of the imaging depends on how deep the ship's echo-sounder can probe. The ocean has an average depth worldwide of about 4,000 metres; a typical navigation sonar reads only to 1,000 metres, but that means it still

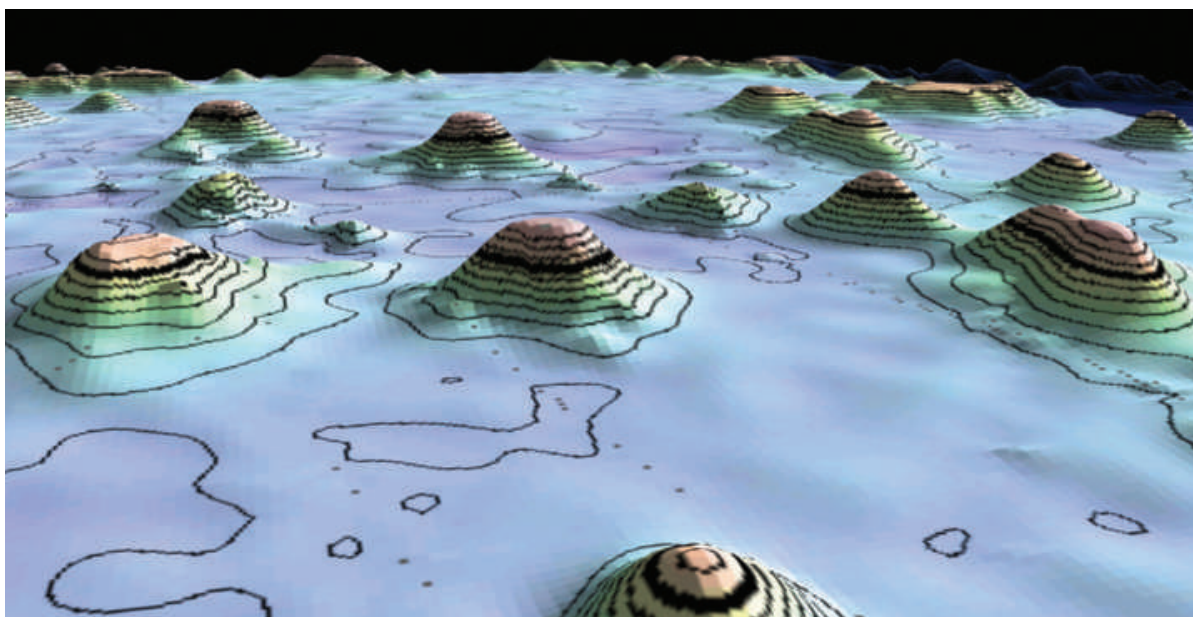

Mountains, mountains everywhere: seamounts are less well mapped than the volcanoes of Mars.

could pick up some tall seamounts.

Government sonar data are typically hoarded for many years. The US Navy, for instance, is soon expected to release a massive cache of sonar survey data that it has gathered over the past few decades, says Christopher Fox, director of the National Geophysical Data Center in Boulder, Colorado; oceanographers hope that it will contain information on many unknown seamounts. Google has also been pushing for such data to be released to incorporate into its Google Ocean feature (see Nature 457, 1065; 2009).
In the meantime, oceanographer David Sandwell of Scripps and his colleagues have created a program to allow anyone to engage in seamount mapping. Soon to be made available online (http://topex.ucsd.edu/marine_topo), the program allows people to superimpose the routes of research ships over ocean bathymetry data that indicate where seamounts may exist. Ships steaming near these huge unprobed regions could then send in their data for analysis.

The trick now is to create an easy way to access and store the data centrally.

Rex Dalton

\section{Research review boards dogged by criticism}

An undercover investigation into the system that regulates human experimentation in the United States has revealed flaws that expose it to 'unethical manipulation', the Government Accountability Office reported last week.

The federal inquiry was launched in January 2008 to probe the network of institutional review boards (IRBs) that oversee research using human patients, such as clinical trials. The boards are often run by universities and hospitals, but, with researchers clamouring for their proposals to be reviewed more quickly, a burgeoning industry of independent, for-profit IRBs has recently emerged.

In a hearing before the House Committee on Energy and Commerce on 26 March, government investigators reported that they had registered fictitious IRBs with the Office for Human Research Protections - including one called Phaké Medical Devices, supposedly based in 'Paynesville, South Carolina'.

At the hearing, protections office director Jerry Menikoff noted that the registration of IRBs is a simple listing process that does not involve background checks. That system was recommended following a previous inspection of the programme, he said.

Investigators also advertised a bogus IRB pledging "fast approvals guaranteed", and naming the fictitious board's president after a three-legged dog called Trooper. Six companies responded to the advert, and one attempted to hire the IRB.

In a separate arm of the inquiry, an intentionally vague research protocol was concocted and submitted to three real IRBs. The proposal called for a litre of a fake gel to be poured into the abdominal cavity of women to ease recovery after surgery. Two of the IRBs rejected the proposal outright, with one board member calling it "the riskiest thing I've ever seen", investigators reported. But one IRB approved the protocol unanimously.

"Our investigation showed the current system is highly vulnerable to unethical or incompetent actors," says Gregory Kutz, managing director of forensic audits and special investigations at the Government Accountability Office.

The report falls short of a comprehensive review of independent IRBs but is still valuable, says Trudo Lemmens, a bioethicist at the University of Toronto in Canada. "It's more or less anecdotal," he says, "but it confirms that there is a problem in how the system is constructed." Heidi Ledford 